\title{
Age-dependent involvement of gut mast cells and histamine in post-stroke inflammation
}

Maria Pilar Blasco ${ }^{1}$, Anjali Chauhan¹, Pedram Honarpisheh¹, Hilda Ahnstedt ${ }^{1}$, John d'Aigle ${ }^{1}$, Arunkumar Ganesan², Sriram Ayyaswamy², Frank Blixt ${ }^{1}$, Susan Venable ${ }^{3}$, Angela Major ${ }^{3}$, David Durgan², Anthony Haag ${ }^{3}$, Julia Kofler ${ }^{4}$, Robert Bryan², Louise D. McCullough ${ }^{1}$ and Bhanu Priya Ganesh ${ }^{1^{*}}$ (D)

\begin{abstract}
Background: Risk of stroke-related morbidity and mortality increases significantly with age. Aging is associated with chronic, low-grade inflammation, which is thought to contribute to the poorer outcomes after stroke seen in the elderly. Histamine (HA) is a major molecular mediator of inflammation, and mast cells residing in the gut are a primary source of histamine.

Methods: Stroke was induced in male C57BL/6 J mice at 3 months (young) and 20 months (aged) of age. Role of histamine after stroke was examined using young $(\mathrm{Yg})$ and aged $(\mathrm{Ag})$ mice; mice underwent MCAO surgery and were euthanized at $6 \mathrm{~h}, 24 \mathrm{~h}$, and 7 days post-ischemia; sham mice received the same surgery but no MCAO. In this work, we evaluated whether worsened outcomes after experimental stroke in aged mice were associated with agerelated changes in mast cells, histamine levels, and histamine receptor expression in the gut, brain, and plasma.

Results: We found increased numbers of mast cells in the gut and the brain with aging. Using the middle cerebral artery occlusion (MCAO) model of ischemic stroke, we demonstrate that stroke leads to increased numbers of gut mast cells and gut histamine receptor expression levels. These gut-centric changes are associated with elevated levels of HA and other pro-inflammatory cytokines including IL-6, G-CSF, TNF-a, and IFN- $\gamma$ in the peripheral circulation. Our data also shows that post-stroke gut inflammation led to a significant reduction of mucinproducing goblet cells and a loss of gut barrier integrity. Lastly, gut inflammation after stroke is associated with changes in the composition of the gut microbiota as early as 24-h post-stroke.

Conclusion: An important theme emerging from our results is that acute inflammatory events following ischemic insults in the brain persist longer in the aged mice when compared to younger animals. Taken together, our findings implicate mast cell activation and histamine signaling as a part of peripheral inflammatory response after ischemic stroke, which are profound in aged animals. Interfering with histamine signaling orally might provide translational value to improve stroke outcome.
\end{abstract}

Keywords: Mast cells, Histamine, Histamine receptor, Cytokines, Post-stroke, Microbiome, Intestinal epithelium

\footnotetext{
*Correspondence: Bhanu.P.Ganesh@uth.tmc.edu

'Department of Neurology, University of Texas McGovern Medical School, Houston, USA

Full list of author information is available at the end of the article
}

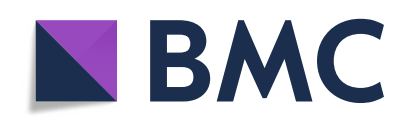

(- The Author(s). 2020 Open Access This article is licensed under a Creative Commons Attribution 4.0 International License, which permits use, sharing, adaptation, distribution and reproduction in any medium or format, as long as you give appropriate credit to the original author(s) and the source, provide a link to the Creative Commons licence, and indicate if changes were made. The images or other third party material in this article are included in the article's Creative Commons licence, unless indicated otherwise in a credit line to the material. If material is not included in the article's Creative Commons licence and your intended use is not permitted by statutory regulation or exceeds the permitted use, you will need to obtain permission directly from the copyright holder. To view a copy of this licence, visit http://creativecommons.org/licenses/by/4.0/. The Creative Commons Public Domain Dedication waiver (http://creativecommons.org/publicdomain/zero/1.0/) applies to the data made available in this article, unless otherwise stated in a credit line to the data. 


\section{Introduction}

Aging is a major risk factor for stroke, stroke-related mortality, and post-stroke complications [1]. Aging is associated with increased inflammation and changes in the immune response to injury $[2,3]$. To date, few studies have investigated the effects of aging on peripheral immune responses after ischemic stroke. Histamine (HA) is a major mediator of acute inflammatory response to tissue injury [4-7]. Among HA-producing cells, mast cells (MCs) are a major source of HA in the early phases of inflammation [8-10]. MCs release stored and newly synthesized HA along with other inflammatory mediators such as proteases, cytokines, and chemokines [9, 11-16]. As the largest immune organ in the body, the gut is a major site of MC progenitors and HA production [17, 18]. Gut MC progenitors constitutively home to the intestinal mucosa $[19,20]$, and upon initiation of the inflammatory response, they are recruited out of the gut environment and mature in a HA-dependent manner [14]. The inflammatory cascade originating in the cerebral vasculature that leads to the systemic immune response by brain ischemia is a major factor in stroke pathophysiology and outcome [21-23].

Accumulating pre-clinical data suggests that stroke leads to a more significant disruption of gut homeostasis in aged mice when compared to young mice [24, 25], but the molecular mediators of these age-dependent changes are poorly defined. MCs are among the firstresponders to tissue injury and secrete large amounts of HA to initiate a cascade of local and systemic inflammatory processes [10]. The diverse effects of HA are determined by the function, structure, tissue distribution, and ligand affinity of the four HA receptor subtypes (H1R through H4R) $[8,26]$. In the gut, the majority of HA receptors are of H1R and H2R subtypes [27, 28].

Using global MC knockout models, one study reported that meningeal MCs worsen stroke-induced brain injury in murine models [29]. Given the limitation of global knockout models however, the role of gut MCs, HA, and HA receptors, where most progenitor MCs are found $[18,30]$, has not been evaluated after stroke. We hypothesized that in aged mice, stroke would induce enhanced peripheral inflammation and an increase in MCs and HA receptor activation in the gut. Therefore, we aim to examine peripheral gut mast cell activation and histamine signaling in response to stroke. Aged MCs are known to be in an increased state of activation [31]. In this work, we evaluated age-dependent changes in local and systemic HA levels, HA receptors, and gut MCs after stroke. Specifically, we investigated how the gut HA and HA receptor levels differ in response to stroke at $6 \mathrm{~h}, 24 \mathrm{~h}$, and 7 days after experimental stroke and compared the response in young $(\mathrm{Yg})$ and aged $(\mathrm{Ag})$ mice. We found that MCs increase with age in both the gut and in the brain. Our data also showed that H2R expression, loss of gut barrier integrity, and elevated plasma HA and other pro-inflammatory cytokines after stroke persist significantly longer in aged mice, when compared to young mice. Gut MCs increased at $24 \mathrm{~h}$ and 7 days after stroke in aged but not in young mice. Lastly, these changes in HA and MCs in the gut were associated with a shift in bacterial phylum and changes in the beta- (between groups) diversity of the gut microbiota in aged mice when pre-stroke gut luminal samples were compared to post-stroke samples. Together, our results suggest that age-dependent differences in HA signaling and gut MCs contribute to the response to stroke. Pharmacological intervention of MC degranulation or inhibition of the HA-mediated inflammatory cascade might be promising therapy to dampen the prolonged phase of inflammation seen with aging.

\section{Materials and methods}

Animal experiments

C57BL/6 J young (3 months) and aged (20 months) male mice were housed in a specific pathogen-free facility (light cycle 12/12 h light/dark). Food and water were provided ad libitum. Due to changes in estrous cycle that has impact on histamine levels in young females [32], we used only males for this study.

\section{Experimental groups}

To examine the role of histamine after stroke in young $(\mathrm{Yg})$ and aged (Ag) mice, mice underwent MCAO surgery and were euthanized at $6 \mathrm{~h}(n=5), 24 \mathrm{~h}(n=5)$, and 7 days $(n=5)$ post-ischemia; sham mice received the same surgery, but the suture was not inserted into the MCA $(n=3,5)$. In total, the groups were divided into Yg-6-sham, Yg-6-stroke, Yg-24-sham, Yg-24-stroke, Ag-6-sham, Ag-6-stroke, Ag-24-sham, and Ag-24-stroke. Seven-day post-ischemic studies were performed only in aged mice (Ag-7d-Sham and Ag-7d-Stroke). A mortality of $20 \%$ was observed in the aged $24 \mathrm{~h}$ MCAo cohort additionally, $40 \%$ mortality was seen at 7 days in aged MCAo mice.

\section{Middle cerebral artery occlusion}

Animals in the respective groups underwent transient focal ischemia under isoflurane anesthesia for $1 \mathrm{~h}$ by occlusion of the right middle cerebral artery (MCA). Body temperature was maintained at $37.0 \pm 1.0^{\circ} \mathrm{C}$ throughout the surgery by an automated temperature control feedback system. One hour after middle cerebral artery occlusion (MCAo), animals were re-anesthetized, and reperfusion was established by the withdrawal of the monofilament. Animals were placed in a recovery cage. All mice were given subcutaneous injections of $0.9 \%$ sodium chloride twice a day for 7 days and were provided 
with wet mash in their cages. Body weight was recorded daily for the duration of the experiments. All experiments were performed by investigators blinded to animal groups and treatments to reduce experimenter bias (Blinded: Due to the size of these animals and stroke having impact on how the animals behave, we used the following methods to blind our samples and the analysis. We followed the blinding of the harvested samples. Tissue harvesting was performed by a blinded individual and analysis is performed by a separate individual who is also blinded. For IHC, the histology core processed the embedding and sectioning of the samples and was performed blinded. Staining was performed and followed up with imaging and analysis blinded. Only after the quantification we un-blinded the samples to allocate them to the respective groups).

\section{Immunohistochemistry}

Formalin fixed, paraffin-embedded intestinal (cecal, ileum) tissue sections $(4 \mu \mathrm{m})$ were incubated overnight at $4{ }^{\circ} \mathrm{C}$ with a primary antibody targeting the mouse antigens (1) histamine receptor 2 (AHR-002, Alomone labs, Israel), (2) Tryptase (ab2378, Abcam, USA), after antigen retrieval according to the manufacturer's instructions. Samples were washed and subsequently incubated with secondary antibody for $45 \mathrm{~min}$ at RT (Histofine simple stain anti-rabbit, 414341F, Nacalai, USA and Alexa fluor ${ }^{\circ}$ 647, ab150131, Abcam, USA). Sections were counterstained either with the diaminobenzidine substrate kit (Nacalai, USA) followed by hematoxylin, or sections were stained with 6-diamidino-2-phenylindole (DAPI, Thermo Fisher, USA) as previously described for visualization of cell nuclei.

\section{Lectin staining to visualize intestinal mucus secreting goblet cells}

Mouse cecal segments were fixed in Carnoy's fixative, embedded in paraffin, and serially sectioned to $5-\mu \mathrm{m}$ sections. Section was stained with hematoxylin and eosin (H\&E) for intestine architecture. Terminal mucin glycans were examined using a panel of FITC-conjugated lectins: Ulex europaeus agglutinin-1 (UEA-1) for terminal fucose; concanavalin A (CONA) for mannose, Dolichos biflorus agglutinin (DBA) for N-acetylgalactosamine, peanut agglutinin (PNA) for galactose, and wheat germ agglutinin (WGA) for $\mathrm{N}$-acetylglucosamine (Vector Laboratories, Burlingame, CA) as previously described [33]. Briefly, de-paraffinized sections were incubated with citrate buffer pH 6 (Vector Labs) for $20 \mathrm{~min}$ in a pressure cooker and blocked with PBS containing 10\% BSA. Sections were then stained in a humidified chamber with FITC-labeled lectin $(10 \mu \mathrm{g} / \mathrm{ml})$ for $1 \mathrm{~h}$ at room temperature. Sections were washed with PBS, counterstained with DAPI (Thermo Fisher, USA) for $5 \mathrm{~min}$ at room temperature, and mounted using aqueous mounting media (Sigma Aldrich). Sections were analyzed by confocal microscopy (Leica Dmi8), and fluorescence was semi-qualitatively calculated by tabulating mean pixel intensity using the ImageJ software (National Institutes of Health).

mRNA in situ hybridization of intestinal tissues mRNA in situ hybridization (ISH) was performed on the distal ileum part of intestinal tissue from the sham and stroke cohort by using the RNAscope $2.5 \mathrm{HD}$ assay system (Advanced Cell Diagnostics, Hayward, CA) with recommended probes [Probe-Mm-Hrh1 (Catalog \# 491141), Probe-Mm-Hrh2 (catalog \# 517751), RNAscope $2.5 \mathrm{HD}$ reagent kit-Red]. ISH scores were generated at $\times$ 200 magnification and recorded using the RNAscope system counting guidelines: number of purple dots (positive stain for H2R mRNA) per villi. Each point represents data from 15 crypts per section per sample.

\section{Fluorescence in situ hybridization}

For intestinal tissue preparation, the small and large intestines were carefully removed immediately following euthanasia and rapidly dissected. Mouse terminal ileum (3-6 cm above the cecum), cecum, and mouse proximal and distal colon were carefully removed, fixed in $10 \%$ formalin fixative at room temperature for $24 \mathrm{~h}$ followed by $70 \%$ ethanol transfer, then rinsed in $100 \%$ ethanol, and embedded in paraffin wax. The tissues were sectioned at a thickness of $4 \mu \mathrm{m}$. These sectioned tissues were used for fluorescence in situ hybridization (FISH) staining as described. Four-micrometer sections were mounted on glass slides, baked at $60^{\circ} \mathrm{C}$ for $1 \mathrm{~h}$, then deparaffinized with xylene, and dehydrated in $100 \%$ ethanol followed by incubation in ddH2O. A previously validated, 5' Cy3'-labeled, EUB338 bacteria-specific probe (Bact338; 5' - GCTGCCTCCCGTAGGAGT-3') which is complimentary to the V1 to V4 region of the 16S rRNA gene that is highly conserved in bacteria domain. The probe was hybridized to the samples by adding $20-25 \mu \mathrm{L}$ of 1:25 dilution probe with hybridization buffer to each slide and placed in a hybridization chamber at $51^{\circ} \mathrm{C}$ for overnight. Nuclei were labeled with DAPI. Intestinal sections from mice in each cage (total 5-6 per group) were utilized to confirm bacterial location. The slides were analyzed using a Leica DMi8 confocal microscope (Leica biosystems, USA) equipped with appropriate filter set for Cy3' fluorescence (ex $550 \mathrm{~nm} / \mathrm{em} 570 \mathrm{~nm}$ ).

\section{Intestinal content collection and 16S rRNA gene sequencing}

Microbiota in the intestinal (cecum and feces) samples were collected from mice and stored in sterile tubes at $-80^{\circ} \mathrm{C}$ until analyzed. Bacteria taxa in each intestinal content samples were analyzed by amplifying the V4-V5 hyper-variable regions of the $16 \mathrm{~S}$ 
rRNA gene using high throughput sequence analysis (Illumina MiSeq platform). Quality filtered 16S rRNA sequences were clustered into operational taxonomic units (OTUs), with 97\% similarity, by closed reference OTUpicking using the UCLUST algorithm and GreenGenes reference database (v13.5) as implemented in Quantitative Insights Into Microbial Ecology (QIIME versions 1.6 and 1.7). Sequences were checked for chimeras using ChimeraSlayer with standard options as implemented in QIIME. Sequences not clustered were identified using the Ribosomal Database Project to the lowest possible taxonomic level. The data were randomly rarefied to 10,000 sequences per sample prior to any downstream analysis.

\section{Murine cytokine measurements in blood plasma by protein multiplex}

Relative amounts of GM-CSF, IFN-gamma, IL-1, IL-6, IL-9, IP-10/CXCL10, MCP-1/CCL2, VEGF-A, and GCSF in the blood plasma were measured using cytokine multiplex kits (Millipore, Billerica, MA, USA). Quantification of cytokines was performed using the MAGPIX system (Austin, TX, USA) according to the manufacturer's instructions. Briefly, $25 \mu \mathrm{l}$ of plasma samples collected from each mouse were thawed completely and diluted with the same amount of Assay Buffer provided in the kits. The assays were performed in duplicate blindly. The reports generated by the MILLIPLEX ${ }^{\oplus}$ Analyst 5.1 Software were carefully reviewed and only cytokines that were within the limit of detection value and below the saturated value were considered. The detection limits for the aforementioned cytokines were between $10,000 \mathrm{pg} / \mathrm{ml}$ and $3.20 \mathrm{pg} / \mathrm{ml}$, respectively.

\section{mRNA gene expression in the intestinal mucosa}

To quantify relative mRNA expression levels of histamine receptor 1 and 2 (H1R and H2R), interferon (IFN)- $\gamma$, tumor necrosis factor (TNF)- $\alpha$, interferon gammainducible protein (IP)-10, interleukin (IL)-6, IL-1, and IL12, RNA was extracted from intestinal mucosa samples (cecum) using the miRNeasy mini kit (QIAGEN). One microgram of RNA was reverse-transcribed to singlestranded cDNA using the RevertAid $\mathrm{H}$ minus First Strand cDNA Synthesis Kit (Thermo Fisher, USA). Reverse transcriptase real-time (RT) PCR was performed using the Quant Studio 3 Real-Time PCR system (Applied Biosystems, USA). The RT-PCR reaction mix (adjusted with $\mathrm{H}_{2} \mathrm{O}$ to a total volume of $20 \mu \mathrm{l}$ ) contained $1 \mu \mathrm{l}$ template DNA, $10 \mu$ l Power SYBR Green PCR master mix (ABI), and $0.5 \mu \mathrm{l}$ of the respective primers $(10 \mu \mathrm{M}$ each). The forward and reverse primers used for IFN- $\gamma$, IP-10, IL-12, IL17 , TNF- $\alpha$, and IL- 6 quantification were described previously $[5,6]$. Relative mRNA target gene expression levels $\left(\right.$ Ratio $=\left[\left(\mathrm{E}_{\text {target }}\right)\right.$ dCPtarget (control-sample) $] /\left[\left(\mathrm{E}_{\text {ref. }}\right)\right.$ dCPref. (control-sample)]) were normalized to the house keeping gene glyceraldehyde 3-phosphate dehydrogenase (GAPDH) and used as a reference. Subsequently, intestinal mucosal cytokine of the sham control group was set to 1.0 and used as the calibrator to identify the relative mRNA fold difference between the sham and stroke groups at $6 \mathrm{~h}, 24 \mathrm{~h}$, and 7 days after stroke.

\section{Toluidine blue staining in human autopsy brain}

Formalin-fixed paraffin-embedded human brain autopsy sections were cut at $30 \mu \mathrm{m}$. The slides were deparaffinized and hydrated. Slides were treated with toluidine blue working solution ( $1 \%$ toluidine blue ethanol solution in $1 \%$ sodium chloride) followed by dehydration. Nuclei were counterstained with hematoxylin. Human brain autopsy samples were obtained from stroke patients. The infarct region is from the cortex. MCs were quantified by counting the positively stained cells around the infarct region per section with a $\times 40$ magnification.

\section{Flow cytometry}

Brain After removal of intestinal tissue, mice were transcardially perfused with $60 \mathrm{ml}$ cold, sterile PBS prior to aseptic removal of the spleen, lung, and brain tissues. Brain tissue was placed in complete Roswell Park Memorial Institute medium 1640 (Lonza) medium and mechanically and enzymatically digested in Collagenase/ Dispase $(1 \mathrm{mg} / \mathrm{mL})$ and DNase $(10 \mathrm{mg} / \mathrm{mL}$; Roche Diagnostics) for $45 \mathrm{~min}$ at $37^{\circ} \mathrm{C}$. Lung tissue was processed similarly with the exception that digestion cocktail contained hyaluronidase (MilliporeSigma, 3000 U/digestion), as well. The cell suspension was filtered through a 70$\mu \mathrm{m}$ filter. Leukocytes were harvested from the interphase of a 70 -to-30\% and 70 -to- $40 \%$ Percoll gradients for the brain and the lung tissues, respectively. MCs were gated for $\mathrm{CD} 45$ positive (+) followed by $\mathrm{FC} \varepsilon \mathrm{R} 1^{+}$with $\mathrm{CD} 117$ $\left(\mathrm{c}-\mathrm{Kit}^{+}\right)$expression.

Intestines Tissue-specific protocols were used to obtain single-cell suspensions. Following the euthanasia by Avertin injection, the small (ileum) and large (cecum and proximal colon) intestines were rapidly removed and placed in ice-cold PBS. The intestinal tissue was opened longitudinally after removal of fat and connective tissues. Fecal content was removed and the tissue was cut into pieces (approximately $1.0 \mathrm{~cm}$ ) after washed in ice-cold PBS. Intestinal tissues were then incubated in $5 \mathrm{~mL}$ of $5 \mathrm{mM}$ ethylenediaminetetraacetic acid (EDTA) in Hank's Buffered Salt Solution (HBSS, Invitrogen, Carlsbad, CA) for $30 \mathrm{~min}$ at $37^{\circ} \mathrm{C}$ with slow rotation $(100 \mathrm{rpm})$. The epithelial cell layer was removed and filtered through $70-\mu \mathrm{m}$ cell strainers. The retrieved intestinal pieces were washed in HBSS and cut into smaller pieces and immersed in $10 \mathrm{~mL}$ digestion solution 
containing 5\% FBS (Sigma-Aldrich, St. Louis, MO), collagenase IV (1.75 mg/mL; Roche, Nutley), and DNase I $\left(0.5 \mathrm{mg} / \mathrm{mL}\right.$; Sigma-Aldrich) at $37^{\circ} \mathrm{C}$ for $45 \mathrm{~min}$ with slow rotation. MCs were gated for $\mathrm{CD} 45$ positive $(+)$ followed by FCeR1 ${ }^{+}$with $\mathrm{CD} 117$ (c-Kit ${ }^{+}$) expression.

\section{Mass spectrometry histamine quantification}

Histamine concentrations were quantified in the blood plasma at 6-h, 24-h post-stroke, and sham control of $\mathrm{Yg}$ and Ag mice. Blood plasma was processed through methanol (Sigma Aldrich, USA) separation. The obtained supernatants were transferred into $3-\mathrm{kDa}$ filtrate and centrifuged for $14,000 \mathrm{~g}, 40 \mathrm{~min}$ at room temperature. Flow-through was collected, and mass spectrometry analysis was performed. Mass spectrometric quantification was performed as follows.

Histamine, formic acid (FA), and perfluoroheptanoic acid (PFHA) were obtained from Sigma-Aldrich (St. Louis, MO). Histamine- $\alpha, \alpha, \beta, \beta-\mathrm{d} 4$ was obtained from $\mathrm{CDN}$ isotopes (Pointe-Claire, Canada). Water and acetonitrile (ACN) were obtained from Fisher Scientific (Waltham, MA). The histamine-d4 internal standard solution was prepared at a concentration of $250 \mathrm{ng} / \mathrm{mL}$ of d4histamine in water with $0.1 \%$ FA. Thirty microliters of internal standard solution was added to $30 \mu \mathrm{L}$ of each sample, vortexed for $1 \mathrm{~min}$, and dried in a SpeedVac for $5 \mathrm{~h}$. Thirty microliters of water:0.1\% FA was added to each sample, vortexed for $1 \mathrm{~min}$ and centrifuged for 5 $\mathrm{min}$ at $10,000 \mathrm{rpm}$. Samples were then loaded into 0.5 $\mathrm{mL}$ autosampler vials for quantification.

Chromatography was performed on a Shimadzu (Kyoto, Japan) Nexera-XR HPLC system consisting of a SIL-20ACxr autosampler, a CTO-20 AC column oven, and 2 LC-20ADxr binary pumps. Samples were loaded onto a Phenomenex (Torrance, CA) $1 \mathrm{~mm} \times 50 \mathrm{~mm}$ phenylhexyl reversed-phased column equipped with a Phenomenex phenylhexyl $4 \mathrm{~mm} \times 2 \mathrm{~mm}$ guard column . The aqueous mobile phase (A) consisted of $\mathrm{H}_{2} \mathrm{O}: \mathrm{ACN}$ : FA:PFHA (99.3:0.5:0.1:0.1 v/v/v/v), and the organic mobile phase (B) consisted of $\mathrm{H}_{2} \mathrm{O}$ :FA $(99.9: 0.1 \mathrm{v} / \mathrm{v})$. Column flow was $80 \mu \mathrm{L} / \mathrm{min}$, and $5 \mu \mathrm{L}$ of sample was injected onto the column and eluted with a constant mobile phase flow rate of $80 \mu \mathrm{L} / \mathrm{min}$. The elution gradient was optimized as follows: started from $10 \% \mathrm{~B}$ and increased to $70 \%$ B over $5 \mathrm{~min}$; ramp to $80 \%$ B for $6 \mathrm{~s}$ and held for $1 \mathrm{~min}$; ramp back to $10 \% \mathrm{~B}$ over $6 \mathrm{~s}$ and maintained at $10 \%$ for a total chromatographic run time of $12 \mathrm{~min}$ to re-equilibrate.

Selected reaction monitoring (SRM) was performed on a Sciex (Framingham, MA) 6500 QTRAP with a Turbo $\mathrm{V}$ source. The mass spectrometer was operated in the positive ion mode under the following conditions: curtain gas 20 psi; collision gas: HIGH; spray voltage $4.5 \mathrm{kV}$; ion source gas 120 psi; ion source gas 220 psi; interface heater temperature $175^{\circ} \mathrm{C}$; Q1 and Q3 resolution: unit; scan time $100 \mathrm{mS}$; declustering potential $100 \mathrm{~V}$; entrance potential $8 \mathrm{~V}$; collision exit potential $10 \mathrm{~V}$. The instrument was calibrated by using Sciex PPG calibration standard and tuned to the manufacturer's specifications. SRM transitions monitored for histamine were $112 \rightarrow$ $95(20 \mathrm{eV})$ and $112 \rightarrow 68(30 \mathrm{eV})$. For histamine-d4, the SRM transitions $116 \rightarrow 99(20 \mathrm{eV})$ and $116 \rightarrow 72(30$ $\mathrm{eV})$ were monitored. Data were acquired with the Analyst ${ }^{\circ}$ Software (ver 1.6.2) and quantification performed using the Multiquant ${ }^{\text {mi }}$ Software (ver 3.0.1).

\section{Statistics}

Data were tested for normal distribution using the Kolmogorov-Smirnov test. Normally distributed data are presented as means with standard deviation while the medians with their range are given for non-normally distributed data. Significance of differences between sham (control) and stroke (experimental) at 6-h, 24-h, and 7days post-stroke mice were analyzed using the one-way analysis of variance test for normally distributed data (or) the Kruskal-Wallis test for non-normally distributed data, followed by either Bonferroni/Tukey's multiple comparison post hoc tests. Differences between sham and stroke at single time-point were analyzed using Student's $t$ test followed by the Mann-Whitney test for non-normally distributed data. Differences between the groups were considered significant at ${ }^{*} P<0.05,{ }^{* *} P<$ 0.01, ${ }^{* * *} P<0.001$. The Prism 5.0 software (Graph Pad Software, Inc., La Jolla, CA, USA) for Windows was used for data presentation and for data analysis. All experiments were performed by an investigator blinded to stroke and age groups during analysis. Differences in Phyla in the gut microbiota of young and aged mice were analyzed using the unweighted UniFrac distance and plotted in a Principal Coordinates Analysis. The UniFrac distance is a measure that takes into account the branch length shared by the young and aged microbiota when placed on a common phylogenetic tree [34, 35].

\section{Results}

Aging is associated with increased number of mast cells (MCs) in the gut and in the brain Aging is an important risk factor for stroke and is accompanied by low-level inflammation [3, 36]. Aging alters the immunological response to stroke [36, 37]. We investigated if aging has an impact on tissue-specific MC populations and if age-associated differences in MCs play a role in post-stroke inflammation. MC progenitors are housed in the intestinal mucosa. Thus, we first investigated changes in the $\mathrm{MC}$ populations in the gut and the brain of naïve Yg (3 months) and Ag (20 months) male WT mice. After exclusion of $\mathrm{B}$ cells, $\mathrm{T}$ cells, macrophages, 
and dendritic cells, MCs were identified as $\mathrm{CD} 45^{+}$ FCER $1^{+} \mathrm{CD} 117 / \mathrm{c}-\mathrm{Kit}^{+}$population. We found a significant increase in relative frequency of MCs, as a percentage of $\mathrm{CD} 45^{+}$population, in both the gut and the brain of $\mathrm{Ag}$ mice compared to $\mathrm{Yg}$ mice (Fig. 1). We then, using human brain samples, investigated the presence of MCs in the infarct area. Human brain autopsy samples from stroke patients showed highly granulated MCs around the infarct area whereas MCs were not detected in young or aged control samples (Supplemental Figure 1 ). We then determined if the increased number of gut MCs was associated with higher levels of circulating HA after stroke in $\mathrm{Ag}$ and $\mathrm{Yg}$ mice.

Stroke leads to elevated HA in the systemic circulation in an age-dependent manner HA is released by resident $\mathrm{MCs}$, as an immediate response to tissue injury and initiator of inflammation $[9,11-16]$. We hypothesized that aging leads to increases in systemic HA levels after stroke. We quantified plasma HA levels at 6 and $24 \mathrm{~h}$ after stroke in Yg (3 months) and Ag (20 months) mice. Mass spectrometry analysis demonstrated that $\mathrm{Yg}$ mice showed no changes in plasma HA levels at 6 and $24 \mathrm{~h}$ $\left(\right.$ Yg: $6-\mathrm{h}=1.12 \pm 0.2$ and $24-\mathrm{h}=1.10 \pm 0.18 \mathrm{ng} \mathrm{ml}^{-1}$ ) after stroke compared to age-matched sham controls. In contrast, Ag mice exhibited an increase in plasma HA levels at $6 \mathrm{~h}$ that was significantly increased at $24 \mathrm{~h}$ after stroke when compared to age-matched shams (Fig. 2a). In line with these systemic changes, brain HA levels were significantly higher at $6 \mathrm{~h}$ after stroke in Ag group when compared to age-matched shams (Fig. 2b). This increased brain HA level was not significant at $24 \mathrm{~h}$, although there was a trend towards increased in HA levels after stroke in the Ag group (Fig. 2b). No changes in brain HA level was observed in the Yg group at either timepoint (data not shown). These findings suggest that aging is associated with increased plasma and brain HA levels after stroke in the acute phase. We speculated that increased systemic HA levels after stroke might also lead to increased HA receptor expression in the gut.

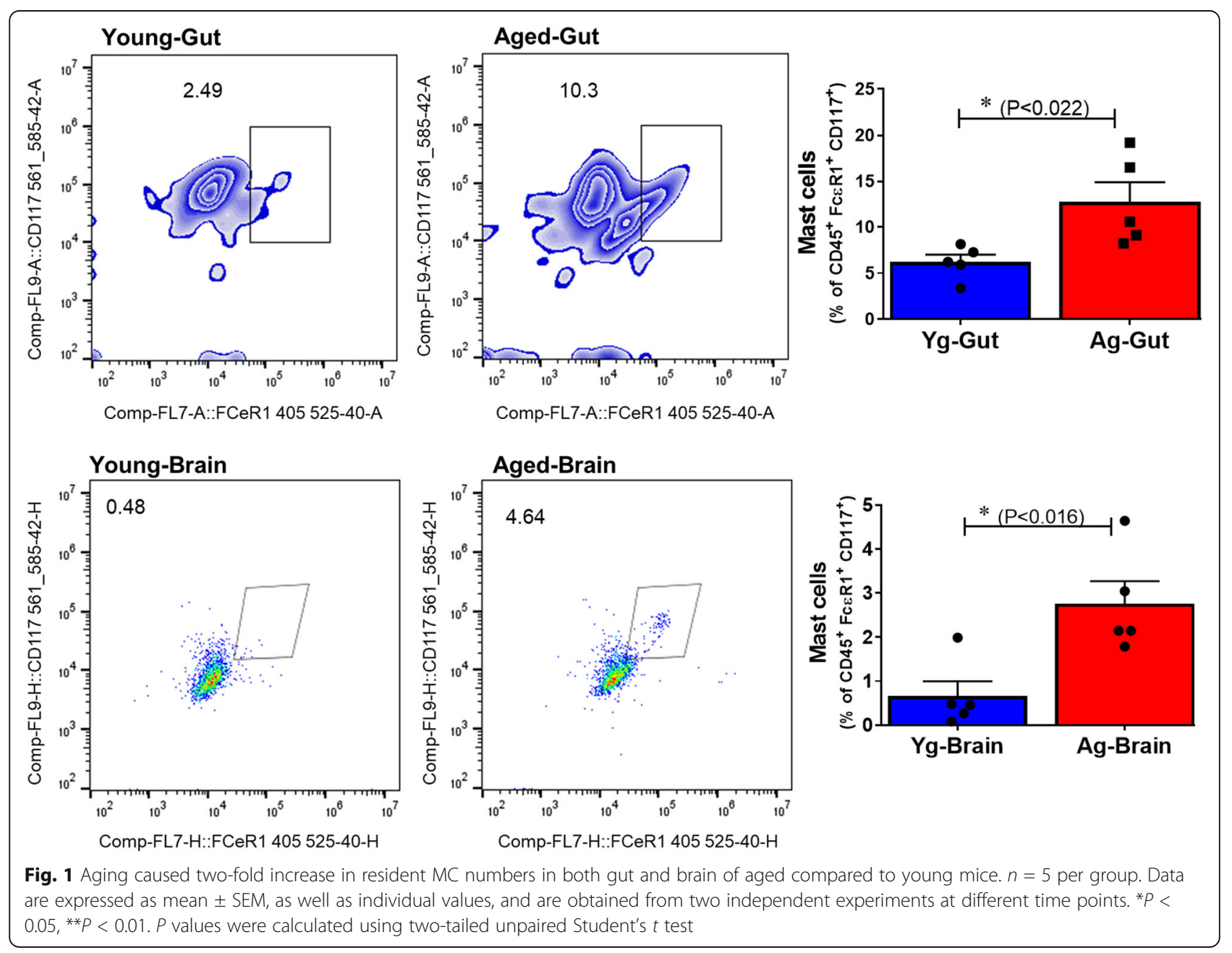




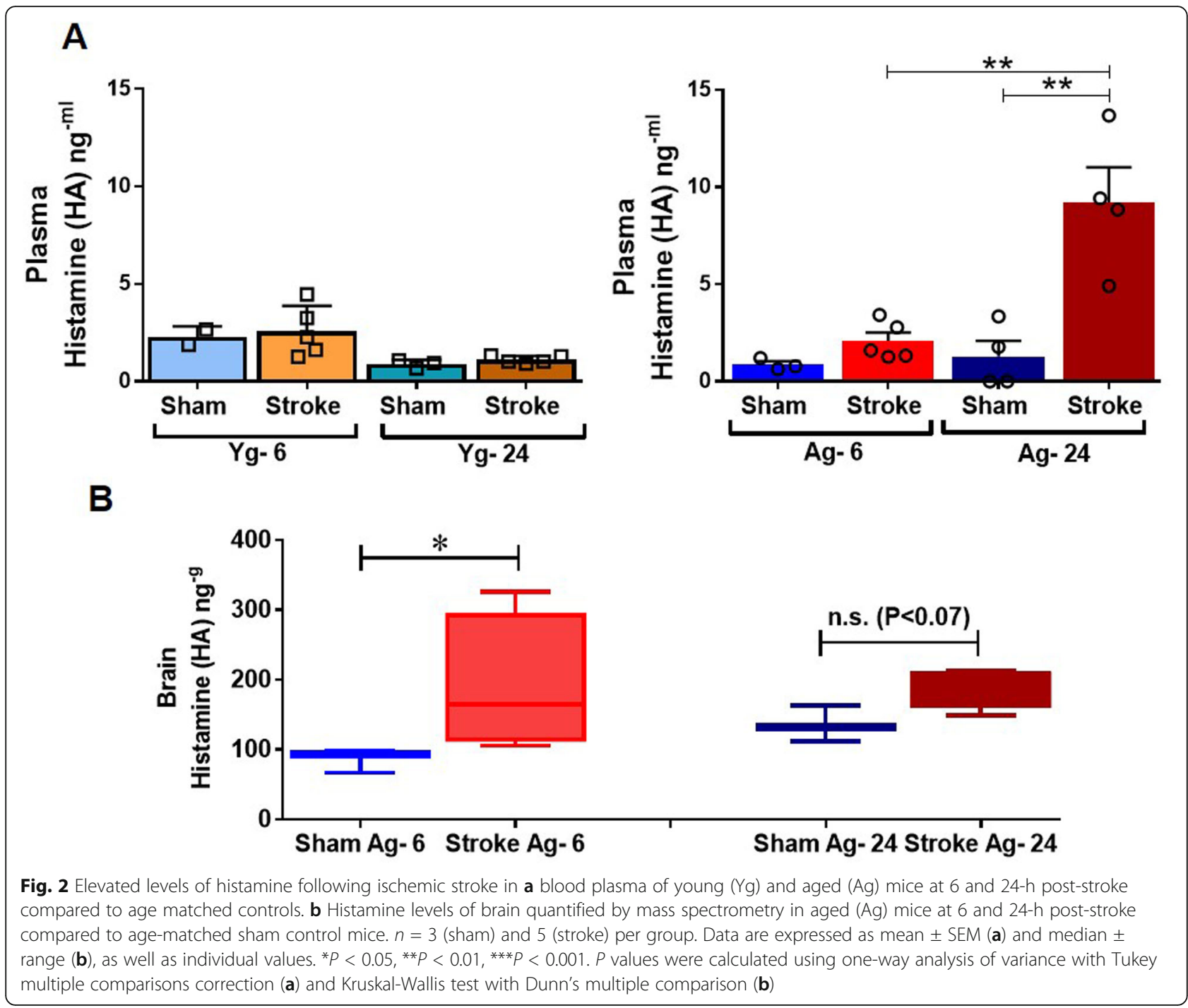

Stroke leads to elevated gut mucosal H2R expression We then determined whether this increase in systemic HA levels after stroke in Ag but not Yg mice is associated with increased expression of the gut-specific HA receptor, $\mathrm{H} 2 \mathrm{R}$ in $\mathrm{Ag}$ but not in $\mathrm{Yg}$ mice after stroke. We performed mRNA gene expression analysis from gut tissues of $\mathrm{Yg}$ and $\mathrm{Ag}$ mice at 6- and 24-h poststroke timepoints. We found that $\mathrm{H} 2 \mathrm{R}$ gene expression was significantly increased in the gut mucosa at $24 \mathrm{~h}$ after stroke in $\mathrm{Ag}$ mice but not in $\mathrm{Yg}$ mice, when compared to age-matched shams (Fig. 3a). Since we observed a significant increase in H2R expression at 24-h post-stroke only in aged mice, we performed additional experiments in $\mathrm{Ag}$ mice to examine the sub-acute effects of stroke on H2R expression in the gut mucosa. Gut tissue was collected from Ag (20 months) sham and stroke groups at 7-days poststroke (7d PS). Ag mice showed significantly increased $\mathrm{H} 2 \mathrm{R}$ expression in the gut at both the protein and mRNA levels within the intestinal mucosa (Fig. $3 \mathrm{~b}, \mathrm{c})$. This increased expression was significant in the lamina mucosa where most of the immune cells reside in the gut tissue. RNA in situ hybridization (Fig. 3c) showed increased H2R mRNA expression in the lamina mucosa, which further supports the notion that there is an increase in H2R protein levels after stroke in the gut epithelium of Ag mice at 7 days PS.

Stroke-induced HA release is associated with increased pro-inflammatory cytokines in both systemic circulation and the gut IL- 6 is a key pro-inflammatory molecule and mediates stroke-induced inflammation [38-40]. IL-6 increases MCs maturation [41] by inducing the FceR1 receptor on MCs [42-45] and by upregulating HA production. In young mice, we found increased levels of plasma IL-6 at 6 -h post-stroke that normalized by $24 \mathrm{~h}$, when compared to age-matched shams. In aged mice however, a significant increase in plasma IL-6 levels 
A

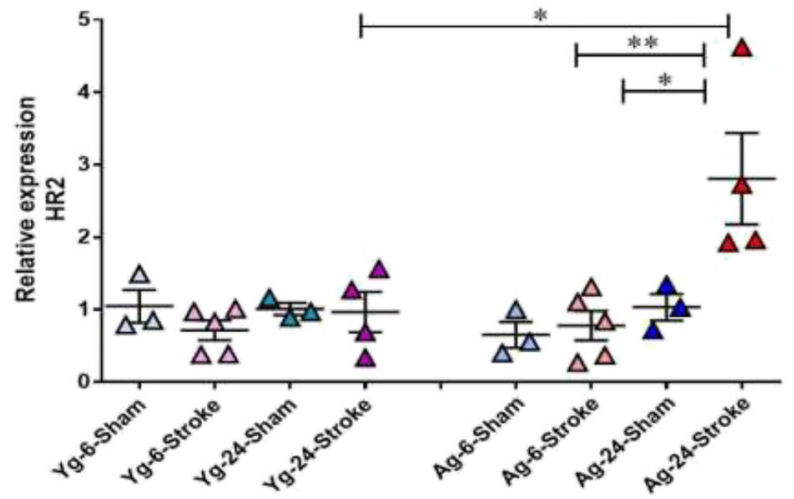

B (i)

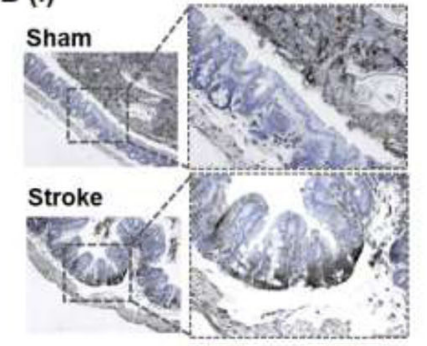

B (ii)
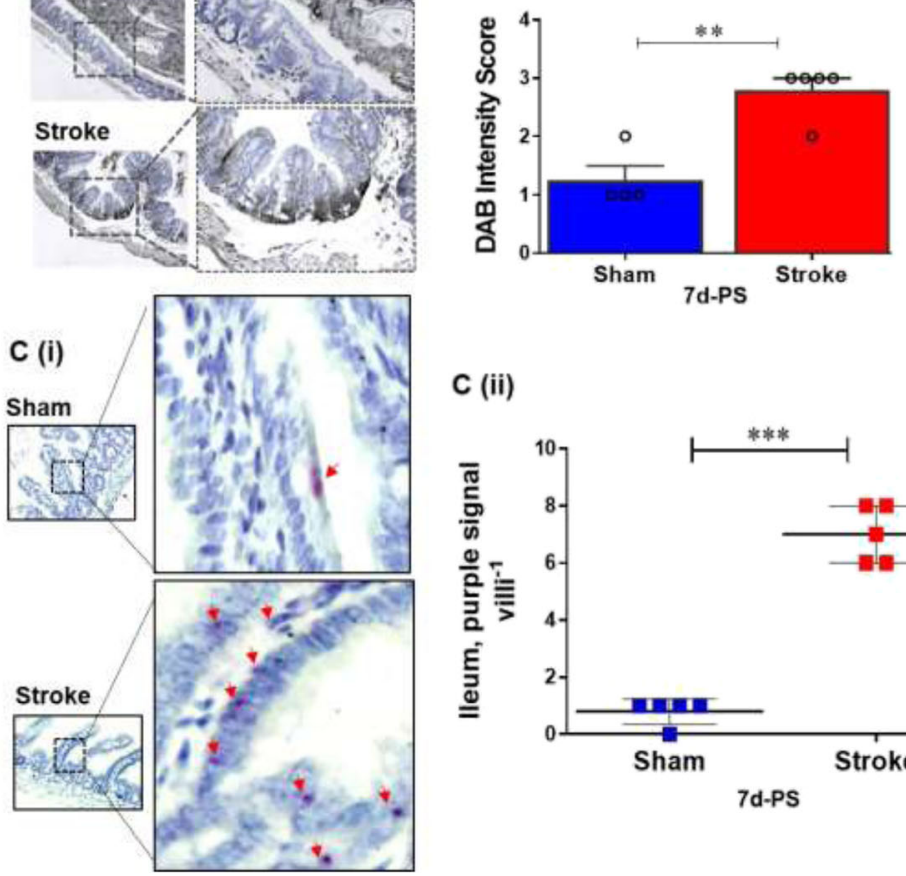

C (ii)

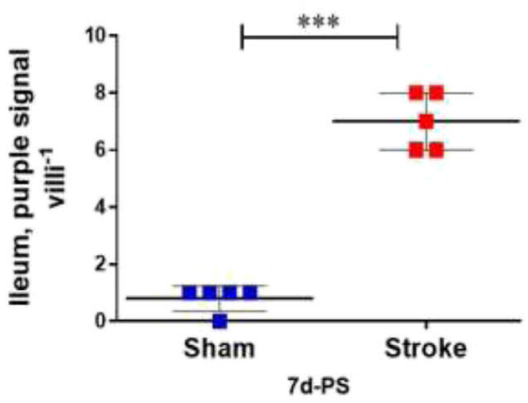

Fig. 3 Increased levels of histamine receptor 2 (HR2) measured in the intestinal samples of young and aged mice for 6-h, 24-h, and 7-days poststroke compared to the age matched controls. a mRNA expression levels of HR2 quantified by qPCR in young and aged mice at 6 and $24 \mathrm{~h}$ poststroke. $\mathbf{b}$ (i) Protein levels of HR2 quantified by IHC followed by image J quantification in aged mice at 7 days post-stroke and $\mathbf{c}$ mRNA levels of HR2 quantified by RNA in situ hybridization and analyzed by image-J in the intestine of Ag mice at 7 days post-stroke. $n=3$ (sham) and 5 (stroke) per group (a) and 5 (sham) and 5 (stroke) per group (b and $\mathbf{c}$ ). Data are expressed as mean \pm SEM (a), (b), and (c), as well as individual values. ${ }^{*} P<0.05$, ${ }^{* *} P<0.01$, ${ }^{* *} P<0.001$. $P$ values were calculated using one-way analysis of variance with Tukey multiple comparisons correction (a) or with two-tailed unpaired Student's $t$ test (b and c). b Brown-HR2 protein; blue-Nuclei (b) purple dots (red arrows)-mRNA HR2

observed at $6 \mathrm{~h}$ persisted up to $24 \mathrm{~h}$ after stroke, when compared to age-matched shams (Fig. 4a).

Our data showed that granulocyte colony-stimulating factor (G-CSF) was significantly increased in the plasma at $6 \mathrm{~h}$ after stroke in both $\mathrm{Yg}$ and $\mathrm{Ag}$ mice compared to agematched shams. However, there was a significant reduction in plasma G-CSF by $24 \mathrm{~h}$ after stroke only in Yg but not in Ag mice, when compared to age-matched shams (Fig. 4b).

In the gut, IL- 6 and TNF- $\alpha$ gene expression levels were significantly higher at 6 -h and 24-h post-stroke in
Ag mice compared to age-matched controls (Fig. 4c, e). This increase was not seen in Yg mice (Fig. 4c, e). IFN- $\gamma$ expression was significantly increased at $24 \mathrm{~h}$ after stroke in Ag mice whereas Yg mice had no change in IFN- $\gamma$ levels at either timepoints when each group was compared to their age-matched shams (Fig. 4d). Interestingly, IL-6 mRNA levels were significantly elevated in the gut even at 7 days after stroke in aged mice compared to the age-matched sham controls (Fig. 4f). These findings support our hypothesis that increased HA and 


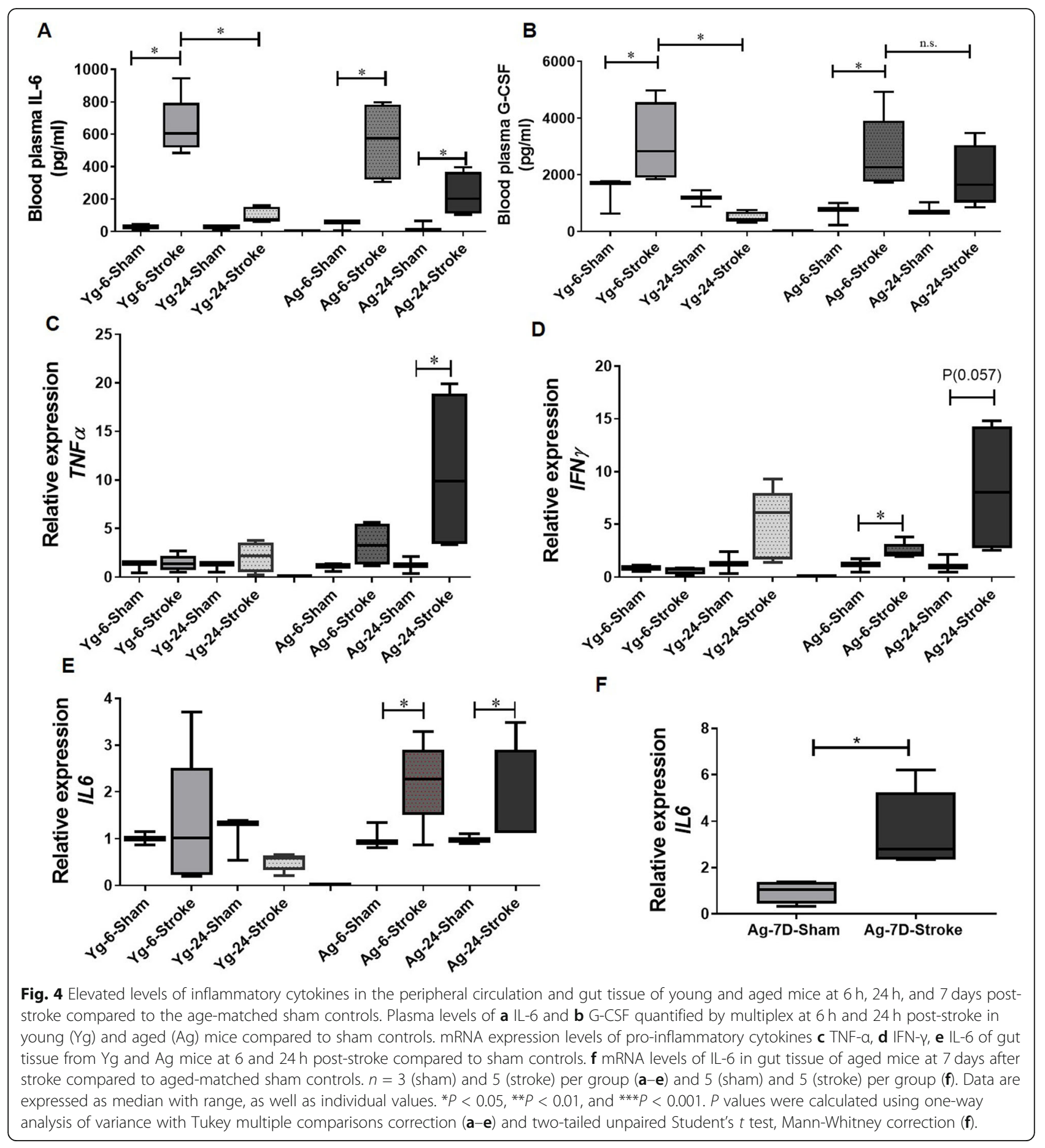

pro-inflammatory cytokines increases in both the plasma and in the gut of aged animals at $24 \mathrm{~h}$ after stroke, when compared to young cohorts.

Stroke leads to increased number of gut MCs MCs are a primary source of HA during acute inflammation. Mucosal MC progenitors constitutively home to the intestinal mucosa and are recruited, then mature, after inflammatory stimuli $[19,20]$. To investigate the cause of increased $H 2 R$ expression, we examined the number of gut MCs after stroke in aged mice. Using immunohistochemistry, we found that young mice show no detectible levels of gut MCs $24 \mathrm{~h}$ after stroke (Fig. 5a). However, a significant increase in gut MCs was seen at $24 \mathrm{~h}$ after stroke in aged mice compared to age-matched 

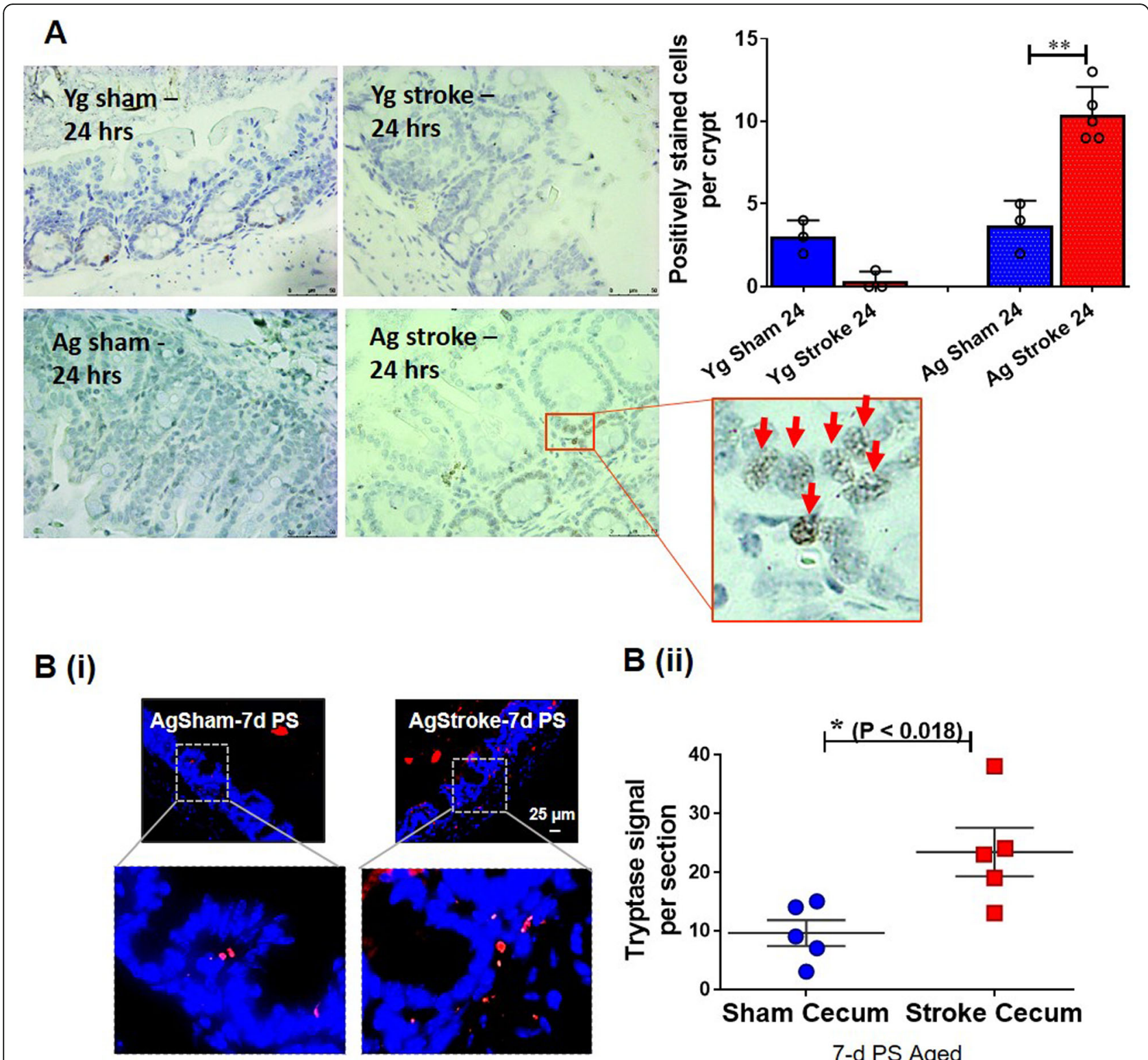

7-d PS Aged

Fig. 5 Increased mast cell (MC) numbers in the gut mucosa measured in the intestinal samples of young and aged mice for $6 \mathrm{~h}, 24 \mathrm{~h}$, and 7 days post-stroke compared to the age matched controls. a MCs quantified by immunohistochemistry in the intestinal samples of young and aged mice at 6-h and 24-h post-stroke compared to their age-matched sham controls. b MCs quantified by fluorescence immunohistochemistry in the intestinal samples of aged mice at 7-days post-stroke and c mRNA levels of HR2 quantified by RNA in situ hybridization and analyzed by image-J in the intestine of Ag mice at 7-days post-stroke. $n=3$ (sham) and 5 (stroke) per group (a) and 5 (sham) and 5 (stroke) per group (b). Data are expressed as mean \pm SEM (a) and (b), as well as individual values. ${ }^{*} P<0.05,{ }^{* *} P<0.01,{ }^{* *} P<0.001 . P$ values were calculated using one-way analysis of variance with Tukey multiple comparisons correction (a) and two-tailed unpaired Student's $t$ test (b). a Red arrows-Mast cell; $\mathbf{b}$ Red-mast cells

shams (Fig. 5a). An increase in the gut MCs, assessed by tryptase signal intensity, was also present 7 days after stroke in aged mice, when compared to age-matched shams (Fig. 5b).

Stroke is associated with reduction in mucussecreting goblet cells in the gut Mucus is secreted by the goblet cells of the gut epithelium and is highly glycosylated [46]. In the presence of inflammation, mucus fucosylation is significantly depleted $[8,47]$. To follow up on our results showing increased gut inflammation in aged mice, we assessed the mucus barrier integrity by quantifying the amount of fucosylated mucin in aged mice. Our results from aged mice at 7-days post-stroke showed a significant reduction in goblet cells filled with fucosylated mucus, when compared to shams 


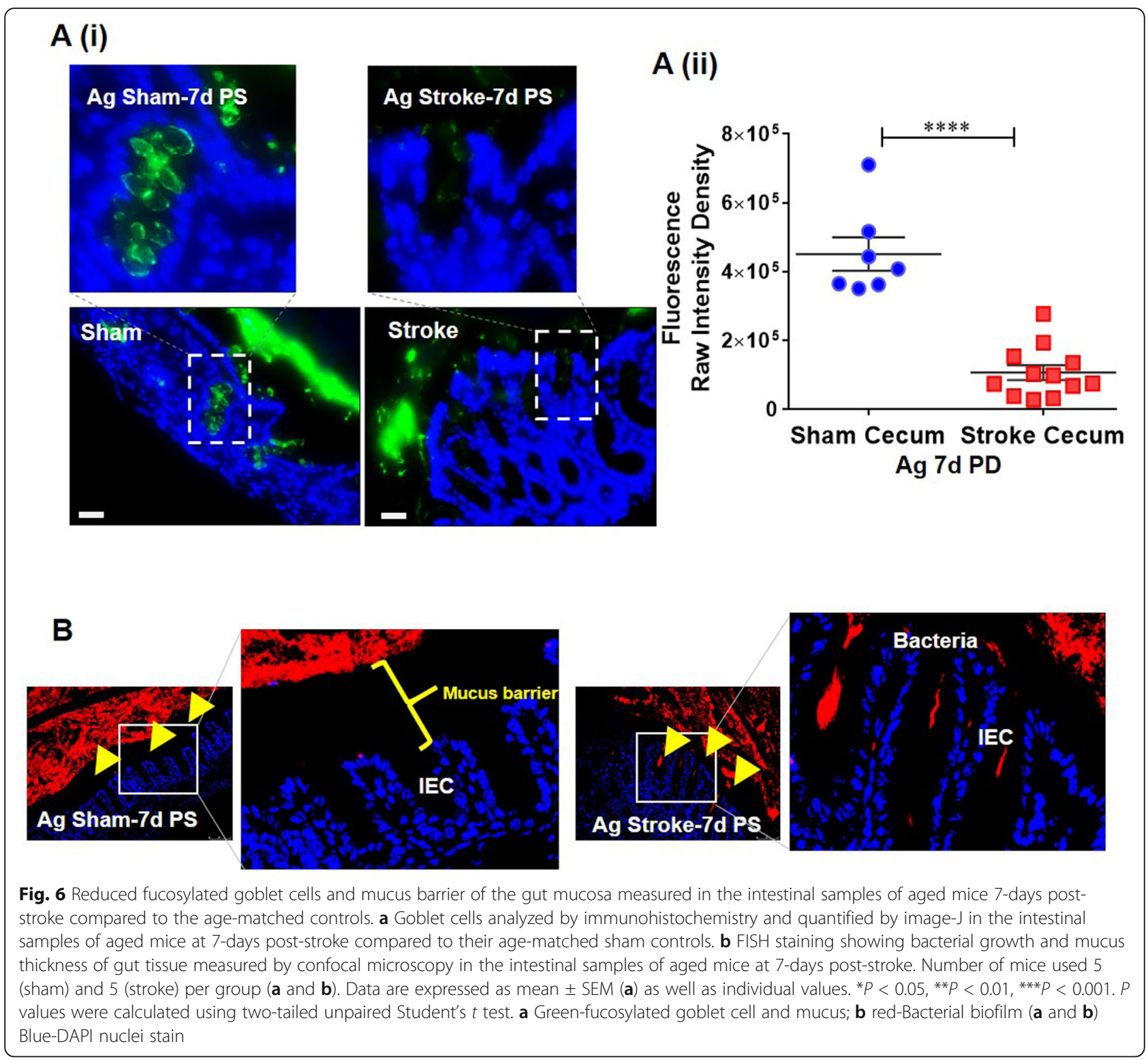

(Fig. 6a). Reduced mucus barrier integrity was also associated with increased bacterial breach observed by fluorescence in situ hybridization of the gut mucosa (Fig. 6b). These findings suggest that increased gut inflammation in aged mice is associated with a loss of gut barrier integrity, which might explain the persistence of poststroke inflammation in aged animals.

Increased H2R and MCs after stroke are associated with dysbiosis of the gut microbiota The composition of gut microbiota can be influenced by intestinal inflammation [48]. We performed 16S rRNA sequencing on gut contents to examine alternations in the microbial diversity caused by stroke-induced inflammation in the $\mathrm{Yg}$ and $\mathrm{Ag}$ mice at $6 \mathrm{~h}, 24 \mathrm{~h}$, and 7 days after stroke and compared these to age-matched sham controls.
Consistent with the increased H2R expression levels and MCs in the gut, aged mice showed a shift in the betadiversity or between-samples diversity, with weighted UniFrac distances by principal coordinate analysis (PCoA), as early as $24 \mathrm{~h}$ after stroke compared to agematched controls (Fig. 7a). Interestingly, we observed an increase in Verrucomicrobiaceae family in aged mice at $24 \mathrm{~h}$ after stroke compared to age-matched shams (Fig. $7 \mathrm{~b})$. These changes were not seen at the earlier timepoint of $6 \mathrm{~h}$ in aged or young (6 and $24 \mathrm{~h}$ ) stroke mice. The alpha-diversity, or within-sample diversity, was not different between sham and stroke mice 7-days poststroke (not shown). Upon visualization of beta-diversity, or between-samples diversity, with weighted UniFrac distances by PCoA, a significant clustering effect $(P=$ 0.006) emerged along the PC1 axis $(69.5 \%$ variation 
A

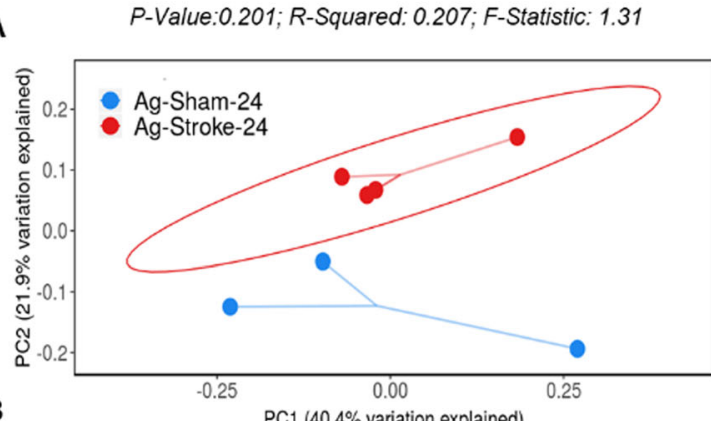

B

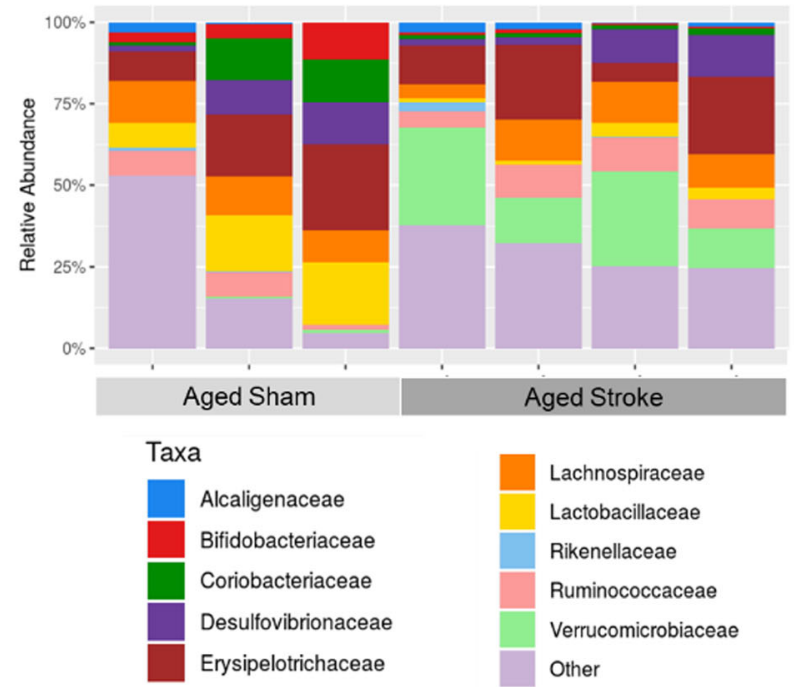

P-Value:0.006: R-Squared: 0.577; F-Statistic: 109
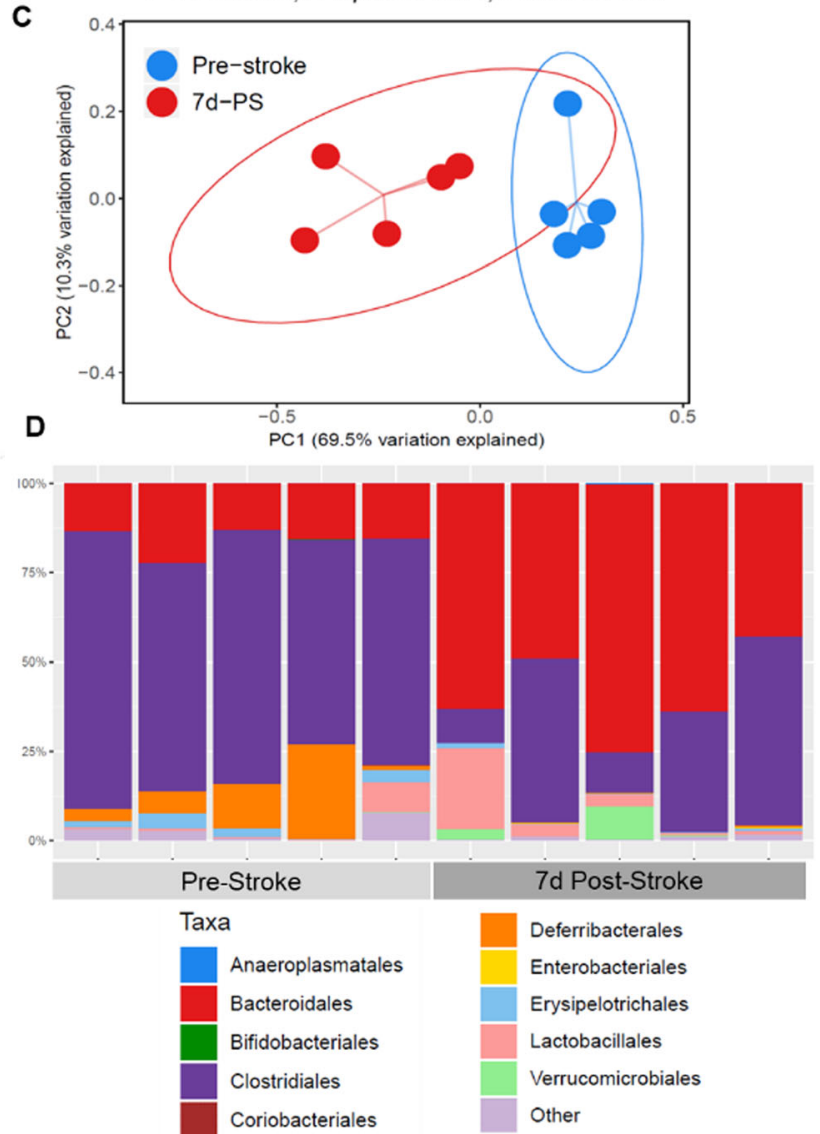

Fig. 7 Compositional differences in gut microbiota by $16 \mathrm{~S}$ rRNA sequencing and GPCR of intestinal luminal content. a Visualization of betadiversity, or between-samples diversity, with weighted UniFrac distances by principal coordinate analysis (PCoA) shows a clustering effect by strain between aged mice at 24-h post-stroke compared to age-matched sham controls and $\mathbf{b}$ corresponding family level bacterial distribution. $\mathbf{C}$ Visualization of beta-diversity, or between-samples diversity, with weighted UniFrac distances by principal coordinate analysis (PCoA) shows a clustering effect by strain between aged mice at 7-days post-stroke compared to age-matched sham controls and $\mathbf{d}$ corresponding order level bacterial distribution. $n=3$ sham and $n=5$ stroke ( $\mathbf{a}$ and $\mathbf{b}$ ); $n=5$ sham and $n=5$ stroke (c and $\mathbf{d}$ )

explained) in 7-days post-stroke Ag mice luminal content compared to pre-stroke Ag mice (Fig. 7c). Closer examination of $16 \mathrm{~S}$ data at the order level showed a significant reduction of Clostridiales and an increase in Bacteroidales in the aged mice 7-days post-stroke compared to pre-stroke mice (Fig. 7d). Overall, our 16S data show that compositional differences in the gut microbiota exist as early as $24 \mathrm{~h}$ after stroke and continued at 7 days after stroke in aged mice, when compared to nonstroke samples (Fig. 7c, d).

\section{Discussion}

Histamine (HA) is an important signaling molecule secreted from resident MCs $[8,9]$ and is necessary for MC maturation [14]. MC progenitors are housed in the gut mucosa and migrate to the site of inflammation upon activation $[19,20]$. MCs are early responders and are involved in the acute blood-brain barrier changes after cerebral ischemia and hemorrhage [49]. Therefore, we hypothesized that stroke would increase gut MC activation, leading to an elevation in systemic HA levels and an increase in peripheral inflammation. Elevated MC signaling is known to increase inflammation due to increased HA release and HR expression [8, 9]. Our results demonstrated that stroke leads to an increase in the gut MC population in aged mice as early as 6-h post-stroke. HA is an important signaling molecule from resident MCs $[8,9]$. Our data support the assumption that an increase in gut MCs leads to an increase in systemic HA and H2R expression levels after stroke in Ag mice. In line with the elevation in H2R expression, we found elevated IL-6 expression levels in the gut mucosa after stroke only in Ag mice. IL-6 is a pro-inflammatory molecule and mediates stroke-induced inflammation [38-40] and also increases MC maturation [41]. IL-6 also upregulates histamine production and induces the 
FceR1 immunoglobulin receptor found on mast cells [42-45]. In addition, we found that mucus secreting fucosylated goblet cells were reduced after stroke in $\mathrm{Ag}$ mice. Fucosylation of mucus is a major determinant of a healthy gut, and reduction in fucosylation is associated with gut inflammation [5, 8, 50, 51]. Of note, these changes were only examined in male mice, as estradiol induces partial release of MCs [52]. As the estrous cycle varies every 4 days in young female mice [32], we focused these initial studies on male mice. Evaluation of aged females would add translational value to these findings in future experiments.

Histamine release is an immediate response from MCs after injury, and this triggers the production of a variety of pro-inflammatory molecules [9-16]. Previous work has shown that an increase in systemic HA levels occurs with aging [30]. In association with altered HA levels, changes in IL-1 $\beta$ and TNF $\alpha$ in the brain have also been reported [53]. Similarly, we observed elevated HA levels in the brain of Ag mice acutely after stroke $(6 \mathrm{~h})$ but not at the sub-acute timepoint of $24 \mathrm{~h}$. In contrast, poststroke HA levels remain high at both acute and subacute phases in the plasma of Ag mice. We then investigated the role of the gut in the stroke-induced elevation of HA. Previous studies have shown that gut mucosal MCs (gMCs) are a major source of HA [17, 18]. Interestingly, mucosal MC progenitors constitutively home to the intestinal mucosa and are recruited and matured during inflammation [19, 20]. Importantly, our data showed a basal increase in resident MCs in the brain and gut of aged mice compared to young mice. Therefore, we believe that the increase in systemic HA induced by stroke is secondary to the increased gut MC population in Ag mice. In support of this hypothesis, we observed a significant increase in the gut MCs at $24 \mathrm{~h}$ after stroke and found this effect to be age-dependent.

Reducing HA signaling may have therapeutic potential. Administration of a H2R antagonist was associated with preserved stroke volume and reduced risk for incident heart failure [54]. Others have found that administration of ranitidine, a H2-receptor antagonist, reduced neuronal death induced by oxygen-glucose deprivation in an in vitro model of ischemia [55]. In line with these observations, we found a significant increase in H2R expression in the gut as early as $24 \mathrm{~h}$ and as late as 7 days after stroke in aged mice. Therefore, we speculate that stroke increases gut MCs, which contributes to severe peripheral inflammation via increased gut $\mathrm{HA}-\mathrm{H} 2 \mathrm{R}$ activation in Ag mice. In line with these findings, we found that pro-inflammatory cytokines, such as IL-6, TNF- $\alpha$, and IFN- $\gamma$ were increased in the gut mucosa of aged mice after stroke. Similarly, we found increased systemic proinflammatory cytokines IL-6 and G-CSF levels in aged mice at both $6 \mathrm{~h}$ and at $24 \mathrm{~h}$ after stroke.
A previous study has reported that MCs derived from meninges worsen damage in murine models of stroke [29]. However, this study used global MC knockout mice that had MCs deleted from all tissues. Therefore, the role of peripheral MCs, specifically those from the gut where most progenitor MCs are found, was not studied. This study is the first evidence that shows the importance of peripheral MCs and their role in stroke in aged animals. Our group has previously shown that stroke leads to increased neuroinflammation in aged animals $[35,36,56]$. We have also shown that the gut is "inflamed" after stroke [35]. However, the initial trigger that connects the brain-gut axis in the response to stroke is not understood. MCs are abundant in the gastrointestinal mucosa [20], and their activation is a primary response to tissue injury [57]. Stroke induces HA accumulation and causes $\mathrm{MC}$ degranulation in the neonatal brain [4]. Interestingly, MCs are also early responders in the regulation of acute blood-brain barrier changes after cerebral ischemia and hemorrhage [49] and likely play a key role in the response to injury. In keeping with our hypothesis, we observed an increase in gut MCs, gut $\mathrm{H} 2 \mathrm{R}$ expression, and circulating HA levels after stroke with age. These changes were not seen in young mice after stroke, reinforcing the value of examining aged mice in experimental stroke studies. This is important as stroke mainly affects older individuals [58]. We believe that the increase in gut MCs at the subacute phase of $24 \mathrm{~h}$ might be an important link in the brain-gut axis and the response to stroke. Future studies to validate these findings with knockout mice are needed to confirm the role of HA and gMCs in post-stroke inflammation. In addition, previous research in our lab has shown changes in infarct volume in aged and young male mice 24-h post-stroke. However, the increased infarct volume and neurological scores observed in young post-stroke mice showed reduced inflammation (measured by $\mathrm{T}$ cells, monocytes, and microglia activation) compared to aged post-stroke mice that showed reduced infarct volume with increased inflammation in the brain [59]. In addition, our lab has previously demonstrated that aged mice brain develops higher hemorrhage transformation than young mouse brain post-stroke [36]. There is a growing body of evidence that inflammatory cell infiltration is predominantly deleterious in the early phase of ischemia with age [60]. MCs, best known as first responders and pro-inflammatory effector cells, play critical roles in the development of inflammation in many disease settings [11]. Previous studies show that the majority of MCs reside in the gut mucosa [57]. Gut pathology leads to increased activation of MCs [61]. In the current study, we have seen increased gut inflammation with changes in gut microbiome. There is evidence demonstrating that the severity of peripheral 
inflammation is key to determining post-stroke recovery [62]. In addition, previous studies have shown that ischemia causes reduced levels of diamine oxidase (DAO) that controls histamine availability [63]. However, aging itself reduces basal gut mucosal DAO levels [64] leading to increased HA levels from MCs in Ag but not in Yg. Since MCs are immediate responders in the injured site, it is of importance to look at histamine levels and mast cell activation post-stroke. Primarily, aged MCs are known to be in an increased state of activation [31]. Changes seen in MCs and inflammation observed in the present study are primarily due to aging effects of stroke. A recent study shows that infarct damage was reduced after stroke in MC-deficient mice, and this was thought to be due to deleterious actions of MCs in the brain [29]. However, this study used whole body knock-out mice and did not analyze the importance of peripheral MCs. Therefore, we assume that focusing on suppressing the mast cell activity in the early phase after stroke might reduce inflammation in aged brain with reduced infiltrating immune cells from the periphery and can be used as therapeutic target for stroke outcome and recovery.

Mucus is secreted by goblet cells of the gut epithelium and it is highly glycosylated [46]. In the presence of inflammation, mucus fucosylation is significantly depleted [8]. Increased inflammation causes reduced mucus synthesis $[5,8]$, allowing luminal bacteria to come in close contact with the gut epithelium triggering further inflammation [47]. The intestinal sections obtained from aged post-stroke male mice at 7 days showed significantly reduced mucus fucosylation in our study. This was associated with increased inflammatory cytokines upregulated in the gut. It is previously known that under inflammatory conditions, goblet cells go through endoplasmic reticulum stress that then leads to loss of goblet cell and behaves like normal epithelial cell $[65,66]$. Also, histamine is known to degranulate goblet cells and cause loss of mucus-filled goblet cells [67, 68]. Since we only found increased systemic and gut mucosal inflammation (histamine and MCs) in aged mice, we assessed the mucus barrier integrity by quantifying the amount of fucosylated mucin only in aged mice at 7-days poststroke to understand the persisting gut dysfunction long after stroke that might have potential impact on poorer stroke outcomes. One may hypothesize that loss of mucus barrier due to inflammatory cascade caused by stroke-induced histamine increase may feedback to further chronic inflammation by increased antigen translocation as seen in Ag stroke.

Our lab has previously demonstrated that gut dysbiosis (imbalanced microbiota composition leading to reduced barrier integrity [69]) plays an important role in the increased peripheral inflammation seen after stroke in aged animals [35]. Significant changes were seen up to 7 days after stroke in aged mice, but not in young mice, re-emphasizing the value of using aged animal models in stroke studies. Similar to the observation presented by Wong et al. [24], the family Verrucomicrobiaceae was the dominant family in the gut of aged mice after stroke. Most bacterial species within this family belongs to Akkermansia muciniphila, a mucin degrader. A. muciniphila is known to contribute to gut inflammation. This increase in mucin-degrading bacteria may be a link between the loss of protective mucus barrier that was seen after stroke. This work demonstrates that HA-HR levels are upregulated in the gut shortly after stroke and this is restricted to aged animals. Interestingly, human brain autopsy samples from stroke patients showed MC around the infarct area (Supplemental Figure 1). In addition, stroke and transient ischemic patients display significant changes in gut microbiota composition reported earlier independent of the comorbidities. This might be due to the sudden severe pain and it is known to cause poor bowel moments [70]. Reduction in bowel moments can indirectly induce dysbiotic microbiome [71]. However, inflammation is known to be the primary cause that leads to long-term health defects, and dysbiosis might contribute to this pathological outcome.

\section{Conclusion}

Post-stroke inflammation is a critical determinant of damage and recovery after stroke [72]. HA secretion after MC degranulation may contribute to inflammation via activation of $\mathrm{H} 2 \mathrm{R}$, blood-brain-barrier disruption, and recruitment of other immune cells to the ischemic brain. Our results show that the increase in gut MCs might be an innate immune response connecting the brain and gut after stroke. This study demonstrates that gut MCs and the $\mathrm{H} 2 \mathrm{R}$ are upregulated after stroke in an age-dependent manner and are one of the primary events that occur following stroke. Our data highlight the importance of gut immune cells, specifically MCs in examining the peripheral response mediated by the brain-gut axis dysfunction after stroke.

\section{Supplementary information}

Supplementary information accompanies this paper at https://doi.org/10. 1186/s12974-020-01833-1.

Additional file 1: Supplemental Figure 1. Visualization of mast cells (MC) by Toluidine blue staining in the infarct area of human autopsy aged stroke brain samples compared to young and age matched controls. Red arrow indicate mast cells in purple stain. (B) Information about human autopsy samples on age, sex, stroke age and MCs found.

\section{Abbreviations}

MC: Mast cells; gMC: Gut mast cells; HA: Histamine; HR2: Histamine receptor 2; MCAO: Middle cerebral artery occlusion; IL: Interleukin; TNF-a: Tumor 
necrosis factor alpha; IFN-ү: Interferon gamma; G-CSF: Granulocyte colony stimulating factor; OTU: Operational taxonomic units

\section{Acknowledgements \\ Not applicable}

\section{Authors' contribution}

BPG was involved in the study design, completion of all experiments, data analysis and interpretation, and manuscript preparation. MPBC contributed to execution of experiments and obtaining raw data together with BPG. AC performed all the strokes. HA was involved in the study design and sample collection. PH contributed to scientific discussion and manuscript preparation. AG, SA, JD, SV, AM, and DD contributed to completion of experiments together with BPG. AH was involved in running mass spectrometry for histamine analysis. JK provided human autopsy brain sections. RB and LDM were involved in the study design, data interpretation, and manuscript editing. The author(s) read and approved the final manuscript.

\section{Funding}

This work was supported by the National Institutes of Health (National Institute for Diabetes and Digestive and Kidney Diseases)-funded Texas Medical Center Digestive Diseases Center (DK56338) DDC-TMC P30DK056338 to B.P.G) (NINDS NS094543 and NIA AG058463 to L.D.M).

\section{Availability of data and materials}

The datasets supporting the conclusions of this article are included within the article and its additional files are available from the corresponding author on reasonable request.

\section{Ethics approval and consent to participate}

All procedures were performed in accordance with $\mathrm{NIH}$ guidelines for the care and use of laboratory animals and were approved by the Institutional Animal care and use committee of the University of Texas Health Science Center Houston.

\section{Consent for publication}

Not applicable.

\section{Competing interests}

The authors declare that they have no competing interests.

\section{Author details}

'Department of Neurology, University of Texas McGovern Medical School, Houston, USA. '2Department of Anesthesiology, Baylor College of Medicine, Houston, USA. ${ }^{3}$ Department of Pathology and Immunology, Baylor College of Medicine, Houston, USA. ${ }^{4}$ Department of Pathology, University of Pittsburg, Pittsburgh, USA.

Received: 17 January 2020 Accepted: 27 April 2020 Published online: 19 May 2020

\section{References}

1. Bentsen $L$, et al. Outcome and risk factors presented in old patients above 80 years of age versus younger patients after ischemic stroke. J Stroke Cerebrovasc Dis. 2014;23(7):1944-8.

2. Durgan DJ, et al. Examining the role of the microbiota-gut-brain axis in stroke. Stroke. 2019;50(8):2270-7.

3. Furman D, et al. Chronic inflammation in the etiology of disease across the life span. Nat Med. 2019;25(12):1822-32.

4. Biran $\mathrm{V}$, et al. Stroke induces histamine accumulation and mast cell degranulation in the neonatal rat brain. Brain Pathol. 2008;18(1):1-9.

5. Ganesh BP, et al. Commensal Akkermansia muciniphila exacerbates gut inflammation in Salmonella Typhimurium-infected gnotobiotic mice. PLoS One. 2013;8(9):e74963.

6. Ganesh BP, et al. Enterococcus faecium NCIMB 10415 does not protect interleukin-10 knock-out mice from chronic gut inflammation. Benef Microbes. 2012;3(1):43-50..

7. Ganesh BP, Versalovic J. Luminal conversion and immunoregulation by probiotics. Front Pharmacol. 2015;6:269.
8. Ganesh BP, et al. Diacylglycerol kinase synthesized by commensal Lactobacillus reuteri diminishes protein kinase C phosphorylation and histamine-mediated signaling in the mammalian intestinal epithelium. Mucosal Immunol. 2018;11(2):380-93..

9. Dong H, Zhang X, Qian Y. Mast cells and neuroinflammation. Med Sci Monit Basic Res. 2014;20:200-6.

10. Bulfone-Paus $\mathrm{S}$, et al. Positive and negative signals in mast cell activation. Trends Immunol. 2017:38(9):657-67.

11. Christy $A L$, et al. Mast cell activation and neutrophil recruitment promotes early and robust inflammation in the meninges in EAE. J Autoimmun. 2013:42:50-61.

12. Jin Y, Silverman AJ, Vannucci SJ. Mast cells are early responders after hypoxia-ischemia in immature rat brain. Stroke. 2009;40(9):3107-12.

13. Kempuraj D, et al. Mast cell activation in brain injury, stress, and posttraumatic stress disorder and Alzheimer's disease pathogenesis. Front Neurosci. 2017:11:703.

14. Nakazawa $\mathrm{S}$, et al. Histamine synthesis is required for granule maturation in murine mast cells. Eur J Immunol. 2014:44(1):204-14.

15. Parsons ME, Ganellin CR. Histamine and its receptors. Br J Pharmacol. 2006; 147(Suppl 1):S127-35.

16. Strbian D, et al. Mast cell stabilization reduces hemorrhage formation and mortality after administration of thrombolytics in experimental ischemic stroke. Circulation. 2007;116(4):411-8.

17. De Winter BY, van den Wijngaard RM, de Jonge WJ. Intestinal mast cells in gut inflammation and motility disturbances. Biochim Biophys Acta. 2012 1822(1):66-73.

18. Bieganski T, et al. Distribution and properties of human intestinal diamine oxidase and its relevance for the histamine catabolism. Biochim Biophys Acta. 1983;756(2):196-203.

19. Dwyer DF, et al. Expression profiling of constitutive mast cells reveals a unique identity within the immune system. Nat Immunol. 2016;17(7):878-87.

20. Hallgren J, Gurish MF. Mast cell progenitor trafficking and maturation. Adv Exp Med Biol. 2011;716:14-28.

21. Tuttolomondo A, et al. Immuno-inflammatory and thrombotic/fibrinolytic variables associated with acute ischemic stroke diagnosis. Atherosclerosis. 2009;203(2):503-8

22. Albanese A, et al. Spontaneous chronic subdural hematomas in young adults with a deficiency in coagulation factor XIII. Report of three cases. J Neurosurg. 2005;102(6):1130-2.

23. Anrather J, ladecola C. Inflammation and stroke: an overview. Neurotherapeutics. 2016;13(4):661-70.

24. Stanley D, Moore RJ, Wong CHY. An insight into intestinal mucosal microbiota disruption after stroke. Sci Rep. 2018;8(1):568.

25. Crapser J, et al. Ischemic stroke induces gut permeability and enhances bacterial translocation leading to sepsis in aged mice. Aging (Albany NY). 2016;8(5):1049-63.

26. Thangam EB, et al. The role of histamine and histamine receptors in mast cell-mediated allergy and inflammation: the hunt for new therapeutic targets. Front Immunol. 2018;9:1873.

27. Sander $L E$, et al. Selective expression of histamine receptors $H 1 R, H 2 R$, and H4R, but not H3R, in the human intestinal tract. Gut. 2006;55(4):498-504

28. Lieberman P. The basics of histamine biology. Ann Allergy Asthma Immunol. 2011;106(2 Suppl):S2-5.

29. Arac A, et al. Evidence that meningeal mast cells can worsen stroke pathology in mice. Am J Pathol. 2014;184(9):2493-504.

30. Maintz L, Novak N. Histamine and histamine intolerance. Am J Clin Nutr. 2007;85(5):1185-96.

31. Chatterjee V, Gashev AA. Aging-associated shifts in functional status of mast cells located by adult and aged mesenteric lymphatic vessels. Am J Physiol Heart Circ Physiol. 2012;303(6):H693-702.

32. Kim H, et al. Effects of the female estrous cycle on the sexual behaviors and ultrasonic vocalizations of male C57BL/6 and autistic BTBR T+tf/J mice. Exp Neurobiol. 2016;25(4):156-62.

33. Engevik MA, et al. Acidic conditions in the NHE2(-/-) mouse intestine result in an altered mucosa-associated bacterial population with changes in mucus oligosaccharides. Cell Physiol Biochem. 2013;32(7):111-28.

34. Hollister EB, et al. Structure and function of the healthy pre-adolescent pediatric gut microbiome. Microbiome. 2015;3:36.

35. Spychala MS, et al. Age-related changes in the gut microbiota influence systemic inflammation and stroke outcome. Ann Neurol. 2018.

36. Ritzel RM, et al. Aging alters the immunological response to ischemic stroke. Acta Neuropathol. 2018;136(1):89-110. 
37. Ritzel RM, et al. Age-associated resident memory CD8 T cells in the central nervous system are primed to potentiate inflammation after ischemic brain injury. J Immunol. 2016;196(8):3318-30.

38. Gabay, C., Interleukin-6 and chronic inflammation. Arthritis Res Ther, 2006. 8 Suppl 2: p. S3.

39. McCarty MF. Interleukin-6 as a central mediator of cardiovascular risk associated with chronic inflammation, smoking, diabetes, and visceral obesity: down-regulation with essential fatty acids, ethanol and pentoxifylline. Med Hypotheses. 1999;52(5):465-77.

40. Scheller J, Ohnesorge N, Rose-John S. Interleukin-6 trans-signalling in chronic inflammation and cancer. Scand J Immunol. 2006;63(5):321-9.

41. Desai, A., et al., IL-6 promotes an increase in human mast cell numbers and reactivity through suppression of suppressor of cytokine signaling 3. J Allergy Clin Immunol, 2016. 137(6): p. 1863-1871 e6.

42. Conti $P$, et al. Interleukin-6 and mast cells. Allergy Asthma Proc. 2002;23(5): 331-5.

43. Kinoshita $T$, et al. Interleukin- 6 directly modulates stem cell factordependent development of human mast cells derived from CD34(+) cord blood cells. Blood. 1999;94(2):496-508.

44. McHale C, et al. Interleukin-6 potentiates FceRI-induced PGD2 biosynthesis and induces VEGF from human in situ-matured skin mast cells. Biochim Biophys Acta. 2018;1862(5):1069-78.

45. Nechushtan $\mathrm{H}$, et al. Inhibition of degranulation and interleukin-6 production in mast cells derived from mice deficient in protein kinase Cbeta. Blood. 2000;95(5):1752-7.

46. Johansson ME, Hansson GC. Mucus and the goblet cell. Dig Dis. 2013;31(3 4):305-9.

47. Pelaseyed T, et al. The mucus and mucins of the goblet cells and enterocytes provide the first defense line of the gastrointestinal tract and interact with the immune system. Immunol Rev. 2014;260(1):8-20.

48. Shi $\mathrm{N}$, et al. Interaction between the gut microbiome and mucosal immune system. Mil Med Res. 2017:4:14.

49. Lindsberg PJ, Strbian D, Karjalainen-Lindsberg ML. Mast cells as early responders in the regulation of acute blood-brain barrier changes after cerebral ischemia and hemorrhage. J Cereb Blood Flow Metab. 2010;30(4): 689-702.

50. Gao C, et al. Histamine $\mathrm{H} 2$ receptor-mediated suppression of intestinal inflammation by probiotic Lactobacillus reuteri. MBio. 2015;6(6):e01358-15.

51. Cornick S, Tawiah A, Chadee K. Roles and regulation of the mucus barrier in the gut. Tissue Barriers. 2015;3(1-2):e982426.

52. Zaitsu $M$, et al. Estradiol activates mast cells via a non-genomic estrogen receptor-alpha and calcium influx. Mol Immunol. 2007;44(8):1977-85.

53. Cacabelos R, et al. Histamine and immune biomarkers in CNS disorders. Mediators Inflamm. 2016;2016:1924603.

54. Leary PJ, et al. Histamine $\mathrm{H} 2$ receptor antagonists, left ventricular morphology, and heart failure risk: the MESA study. J Am Coll Cardiol. 2016; 67(13):1544-52.

55. Malagelada $\mathrm{C}$, et al. Histamine $\mathrm{H}$ 2-receptor antagonist ranitidine protects against neural death induced by oxygen-glucose deprivation. Stroke. 2004 35(10):2396-401.

56. Chauhan A, et al. Myeloid-specific TAK1 deletion results in reduced brain monocyte infiltration and improved outcomes after stroke. J Neuroinflammation. 2018;15(1):148

57. Galli SJ, Maurer M, Lantz CS. Mast cells as sentinels of innate immunity. Curr Opin Immunol. 1999:11(1):53-9.

58. Benjamin EJ, et al. Heart Disease and Stroke Statistics-2019 Update: a report from the American Heart Association. Circulation. 2019;139(10): e56-e528.

59. Manwani $B$, et al. Differential effects of aging and sex on stroke induced inflammation across the lifespan. Exp Neurol. 2013;249:120-31.

60. Jin R, Yang G, Li G. Inflammatory mechanisms in ischemic stroke: role of inflammatory cells. J Leukoc Biol. 2010;87(5):779-89.

61. Akhavein MA, et al. Allergic mastocytic gastroenteritis and colitis: an unexplained etiology in chronic abdominal pain and gastrointestinal dysmotility. Gastroenterol Res Pract. 2012;2012:950582.

62. Chapman $\mathrm{KZ}$, et al. A rapid and transient peripheral inflammatory response precedes brain inflammation after experimental stroke. J Cereb Blood Flow Metab. 2009;29(11):1764-8

63. Wollin A, Navert H, Bounous G. Effect of intestinal ischemia on diamine oxidase activity in rat intestinal tissue and blood. Gastroenterology. 1981; 80(2):349-55.
64. Baylin SB, et al. Age-related abnormalities of circulating polyamines and diamine oxidase activity in cystic fibrosis heterozygotes and homozygotes. Pediatr Res. 1980;14(8):921-5

65. Kaser A, Blumberg RS. Endoplasmic reticulum stress and intestinal inflammation. Mucosal Immunol. 2010;3(1):11-6.

66. McGuckin MA, et al. Mucin dynamics and enteric pathogens. Nat Rev Microbiol. 2011;9(4):265-78.

67. Fan $\mathrm{XH}$, Cheng L, Yan AH. Ameliorative effect of acetylshikonin on ovalbumin (OVA)-induced allergic rhinitis in mice through the inhibition of Th2 cytokine production and mast cell histamine release. APMIS. 2019; 127(10):688-95.

68. Hayashi D, et al. Role of histamine and its receptor subtypes in stimulation of conjunctival goblet cell secretion. Invest Ophthalmol Vis Sci. 2012;53(6): 2993-3003.

69. Turner JR. Intestinal mucosal barrier function in health and disease. Nat Rev Immunol. 2009;9(11):799-809.

70. Barletta JF. Clinical and economic burden of opioid use for postsurgical pain: focus on ventilatory impairment and ileus. Pharmacotherapy. 2012; 32(9 Suppl):12S-8S.

71. Ohkusa T, et al. Gut microbiota and chronic constipation: a review and update. Front Med (Lausanne). 2019;6:19.

72. Broughton BR, et al. Post-stroke inflammation and the potential efficacy of novel stem cell therapies: focus on amnion epithelial cells. Front Cell Neurosci. 2012:6:66

\section{Publisher's Note}

Springer Nature remains neutral with regard to jurisdictional claims in published maps and institutional affiliations.
Ready to submit your research? Choose BMC and benefit from:

- fast, convenient online submission

- thorough peer review by experienced researchers in your field

- rapid publication on acceptance

- support for research data, including large and complex data types

- gold Open Access which fosters wider collaboration and increased citations

- maximum visibility for your research: over $100 \mathrm{M}$ website views per year

At BMC, research is always in progress.

Learn more biomedcentral.com/submissions 